RICYDE. Revista Internacional de Ciencias del Deporte doi: $10.5232 /$ ricyde

Rev. int. cienc. deporte

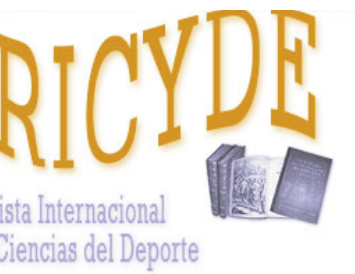

RICYDE. Revista Internacional de Ciencias del Deporte VOLUME XIV - YEAR XIV

Pages:268-279 ISSN:1885-3137

Issue: 53 - July - 2018

\title{
Freestyle stroke parameters of national level swimmers with physical impairments \\ Parámetros de nado en el estilo libre de nadadores de nivel nacional con discapacidad física
}

\author{
Javier Pérez-Tejero1,2, Alberto Almena1,2, Javier Coterón², Archit Navandar ${ }^{2}$ \& Santiago Veiga ${ }^{2}$
}

1. Catedra "Fundación Sanitas" de Estudios sobre Deporte Inclusivo, Facultad de Ciencias de la Actividad Física y del Deporte-INEF, Universidad Politécnica de Madrid. Spain

2. Facultad de Ciencias de la Actividad Física y del Deporte-INEF, Universidad Politécnica de Madrid. Spain

\begin{abstract}
Swimmers with physical impairments during competition for freestyle swimming are grouped according to their functional classification in ten classes. Stroke length, stroke rate, stroke index and clean swimming speed have been studied previously at elite level, but not at national level. Therefore, the aim of this study was to assess the four mentioned variables and performance time regarding functional class and gender in a sample of national level swimmers with physical impairments at the 100 m freestyle. Fourteen female (classes S4, S5, S7; S8, S9 and S10) and twenty nine male (classes S4, S5, S6, S7 S8, and S10) swimmers were recorded during the Winter Spanish Championship for Adapted Swimming. Classical fixed distances method was used for race analysis. Based on the results, stroke length, stroke index, clean swimming speed (and not stroke rate) values increased and turn time decreased significantly $(p<0.01)$ according to the functional class for both males and females from S4 up to S10; with the exception of the S5 male class, with better results (not significant, ns) than S8 in stroke index, or than S7 for clean swimming speed. Significant differences in stroke rate, stroke length and time for males between first and second lap were found, while differences were registered in stroke rate, stroke index, clean swimming speed and time for females. The presented profiling allows to frame performance for long term development of swimmers with physical impairments and also coaches can use the results to determinate the best relationship between stroke rate and stroke length for their swimmers, advice development and talent identification.
\end{abstract}

Key words: swimming; physical impairment; gender; normative values; paralympic sport.

\section{Resumen}

Los nadadores con discapacidad física durante la competición de estilo libre se agrupan según su clasificación funcional en diez clases. La longitud, frecuencia e índice de brazada y la velocidad de nado se han estudiado previamente a nivel de élite, pero no a nivel nacional. Por lo tanto, el objetivo de este estudio fue evaluar las cuatro variables mencionadas y el tiempo de prueba con respecto a la clase funcional y el género en una muestra de nadadores de nivel nacional con discapacidades físicas en la prueba de 100 m estilo libre. Catorce mujeres (clases S4, S5, S7, S8, S9 y S10) y veintinueve hombres (clases S4, S5, S6, S7, S8 y S10) fueron grabados durante el Campeonato de España de Invierno de Natación Adaptada. Posteriormente se utilizó el método clásico de distancias fijas clásicas para el análisis de la prueba. En base a en los resultados obtenidos, los valores de longitud e índice de brazada y de la velocidad de nado (y no de la frecuencia de brazada) aumentaron mientras que el tiempo de viraje disminuyó significativamente $(\mathrm{p}<0,01)$ según la clase funcional para hombres y mujeres de $\mathrm{S4}$ a S10; con la excepción de la clase masculina S5, con mejores resultados que la clase S8 en el índice de brazada, o que S7 para la velocidad de nado. Se encontraron diferencias significativas en el índice, longitud de brazada y el tiempo de prueba en los hombres entre el primer y segundo segmento, mientras que se registraron diferencias en índice, longitud de brazada, velocidad y el tiempo en mujeres. El análisis presentado permite enmarcar el rendimiento de nadadores con discapacidad física en esta prueba con el fin de facilitar un adecuado asesoramiento y desarrollo a largo plazo, así como la identificación de talento, por parte de los entrenadores.

Palabras clave: natación; discapacidad física; género; valores de referencia; deporte paralímpico.

Correspondence/correspondencia: Javier Pérez-Tejero

Catedra Fundación Sanitas de Estudios sobre Deporte Inclusivo, Facultad de Ciencias de la Actividad Física y del Deporte-INEF, Universidad Politécnica de Madrid. Spain

Email: j.perez@upm.es 
Pérez-Tejero, J.; Almena, A.; Coterón, J.; Navandar, A., \& Veiga, S. (2018). Freestyle stroke parameters of national level swimmers with physical impairments. RICYDE. Revista internacional de ciencias del deporte. 53(14), 268-279. https://doi.org/10.5232/ricyde2018.05307

\section{Introduction}

$\mathrm{T}$ he World Para Swimming, the governing board for competitive swimming for persons with disabilities at the International Paralympic Committee (IPC), established a sportspecific classification that allows categorization of swimmers into one of 10 different sport classes based on their physical impairments for freestyle, breaststroke, backstroke and butterfly (International Paralympic Committee Swimming, 2015; International Paralympic Committee Swimming, 2015b). Swimming is the only para-sport that combines different disabilities, such as amputees, cerebral palsy, spinal cord injuries and other disabilities within the same class (Daly and Martens, 2011). The classification is not responsible for assessing impairment presented by the swimmer, but its impact on his/her athletic performance (Tweedy and Vanlandewijck, 2011). This system also governs the competition in swimmers with physical impairment being in a process of constant evolution, where some modifications as a result of annual General Assembly of the IPC each two years (Burkett, 2011) are applied over time.

Regardless of functional class to which the swimmer is assigned, the main objective set is to cover the competition distance using the least possible time. According to Hay and Guimaraes (1983), the competition time can be divided into three segments, the start time (ST), clean swimming time (CST) and the turn time (TT). The CST is characterized by the segment where the swimmer performs a series of cyclical strokes which represent around 75$80 \%$ of the total distance (Arellano and Sánchez, 2002), this being defined by the start or end of the remaining segments in the swimming distance. The speed during CST is the result of the stroke rate (SR) and the stroke length (SL): the relationship between them and their influence on the CST has been widely studied in swimmers without impairments and it has consistently been observed that their relationship with performance is highly individual, depending on the characteristics of the swimmer and the style or the distance swum (Arellano, Brown, Cappaert, and Nelson, 1994; Chengalur and Brown, 1992; Chollet, Pelayo, Delaplace, Tourny, and Sidney, 1997).

In the field of swimmers with physical impairments, first studies date back to the late 90s, so literature available is not as extensive as mainstream swimming. Sport science studies of the $100 \mathrm{~m}$ freestyle finalist at the 2000 Sydney Paralympic Games found that differences in velocity between swimmers were more related to SL than in SR (Daly, Djobova, Malone, Vanlandewijck, and Steadward, 2003). Other studies (Daly, Malone, Vanlandewijck, and Steadward, 1999; Djobova, Mavromati, and Daly, 2002; Pelayo, Sidney, Moretto, Wille, and Chollet, 1999) have shown how SL increased significantly as did the functional class. Regarding SR, no significant differences were found between sport classes and/or swimmers without impairments (Pelayo et al., 1999). At the same time, in this same study, while comparing genders, a significant difference was only found in the SL values, which were found to be higher among the males. It was also found that the race was won or lost in the second half of each lap and differences in CSS were more related to SL than SR.

Stroke index (SI) is the product of the SL and CSS and has been used as an indicator of efficiency and economy in swimming (Arellano and Sánchez, 2002). This is considered a good indicator of the efficiency because the swimmer can achieve high speed while maintaining large SL (Malone, Sanders, Schiltz, and Steadward, 2001). However, few studies have been analysed SI in swimmers with physical impairments. In this regard, Pelayo et al. (1999) in their study of 119 top level swimmers with disability found that SL was significantly related with swimming speed, whereas SR was not. SL (ranging from $1.05 \pm$ 0.40 in $\mathrm{S} 3$ to $1.82 \pm 0.11$ in $\mathrm{S} 10$ for males and from $0.76 \pm 0.25$ in $\mathrm{S} 3$ to $1.54 \pm 0.17$ in $\mathrm{S} 10$ for females) and SI (ranging from $0.8 \pm 0.4$ in S3 to $2.9 \pm 0.2$ in S10 for males and from $0.4 \pm$ 
Pérez-Tejero, J.; Almena, A.; Coterón, J.; Navandar, A., \& Veiga, S. (2018). Freestyle stroke parameters of national level swimmers with physical impairments. RICYDE. Revista internacional de ciencias del deporte. 53(14), 268-279. https://doi.org/10.5232/ricyde2018.05307

0.2 in S3 to $2.1 \pm 0.4$ in S10 for females) values were also significantly related with velocity values in male and female swimmers, being this variables significantly higher in males than females in each class group and also comparing with able-bodied swimmers. These authors also suggested that SI could be used as a sensitive and objective criterion to assess swimmers with physical impairments in relation to their classification.

However, there is a lack of existing knowledge concerning possible differences with lower competitive level swimmers with physical impairments in SI and other related stroke parameters. Data on what distinguishes an elite to an average performance level are essential for developing swimmers to higher levels of expertise or for talent identification (ElferinkGemser, Kannekens, Lyons, Tromp, and Visscher, 2010; Nasirzade, Sadeghi, Sobhkhiz, Mohammadian, Nikouei, Baghaiyan, and Fattahi, 2015). Also, different classes of swimmers with physical impairment do not possess the same skill level for start, turn and finish time, suggesting that different strategies are evident between Paralympic swimming classes (Burkett, 2011); that's why studies evaluating different level of skill of these classes are strongly needed for performance profiling, target results determination and training screening along swimmers' long term development. Therefore, the aim of this study was to assess SI and other relevant stroke parameters in national level swimmers with physical impairments at the $100 \mathrm{~m}$ freestyle event, analysing its relationship with functional classification and gender, depending also the race segment (lap).

\section{Participants}

\section{Methodology}

Swimmers with physical impairments participating at the $100 \mathrm{~m}$ freestyle event were studied in real competitive conditions during the Winter Spanish Championship for Adapted Swimming (Málaga, 2010). To participate in the competition swimmers had to establish a minimum time in previous competition. The sample consisted of a total of 43 participants belonging to the functional classes S4 to S10, of which 14 were female (3 class S4, 3 class S7, 2 class S8, 4 class S9 and 2 class S10; no participants for S5 and S6 classes) and 29 male (4 class S4, 3 class S5, 9 class S6, 3 class S7, 7 class S8 and 3 class S10). There were no S9 male swimmers neither S5 and S6 female swimmers in this competition. Before competition, the present study was approved by the Technical University of Madrid ethical committee and written informed consent was obtained from all the swimmers participating at the $100 \mathrm{~m}$ swimming event. The study was conducted according to the Declaration of Helsinki on research with human beings.

\section{Procedures}

The competition was carried out in a standard Olympic size swimming pool with dimensions of $50 \times 25 \mathrm{~m}$ and a uniform depth of $2.10 \mathrm{~m}$ divided into 10 lanes. For the competition, only the 8 central lanes were used, excluding the ones on the sides. Three stationary high speed cameras Casio model "Exilym" on tripods were placed on the stands on one side of the pool, capturing all the pool from a lateral view (Figure 1). The recording frequency was $25 \mathrm{~Hz}$ and the model for race analysis established by Arellano and Sanchez (2002) was applied. To determine the different segment times and for calibration purposes, cones were placed to coinciding with the boundaries between the different segments of the race used in the fixed distance method (Veiga, Cala, Mallo, and Navarro, 2013): at $7.5 \mathrm{~m}$ and $15 \mathrm{~m}$ from the start and $7.5 \mathrm{~m}$ from the finish wall. The cones at $15 \mathrm{~m}$ were used to mark the start time (ST) and the beginning of the first clean swimming time (CST1), and the cones at $7.5 \mathrm{~m}$ at the turning wall mark the end of the CST1. The clean swimming time in the second lap (CST2) began 
Pérez-Tejero, J.; Almena, A.; Coterón, J.; Navandar, A., \& Veiga, S. (2018). Freestyle stroke parameters of national level swimmers with physical impairments. RICYDE. Revista internacional de ciencias del deporte. 53(14), 268-279. https://doi.org/10.5232/ricyde2018.05307

when the swimmer crossed with the head the cone placed at $7.5 \mathrm{~m}$ from the end of the turning wall at the end of the turn, and reached the cone at $7.5 \mathrm{~m}$ from the start wall. The calibration procedure was carried out the previous day while recording other races and analysing them, later checking if the references placed on the sides of the pool were captured correctly.

Then the surrounding area was isolated to prevent the passage of spectators, and the exact location of the cameras was marked on the ground, and cameras were not moved anymore during competition recording. The day of the competition, 12 races in total were filmed separately. The recording was started at the time that swimmers climbed the platform and the referee raised his hand to indicate that the swimmers must be "on their marks", and ended when the last swimmer touched the electronic timing panel, after the race.

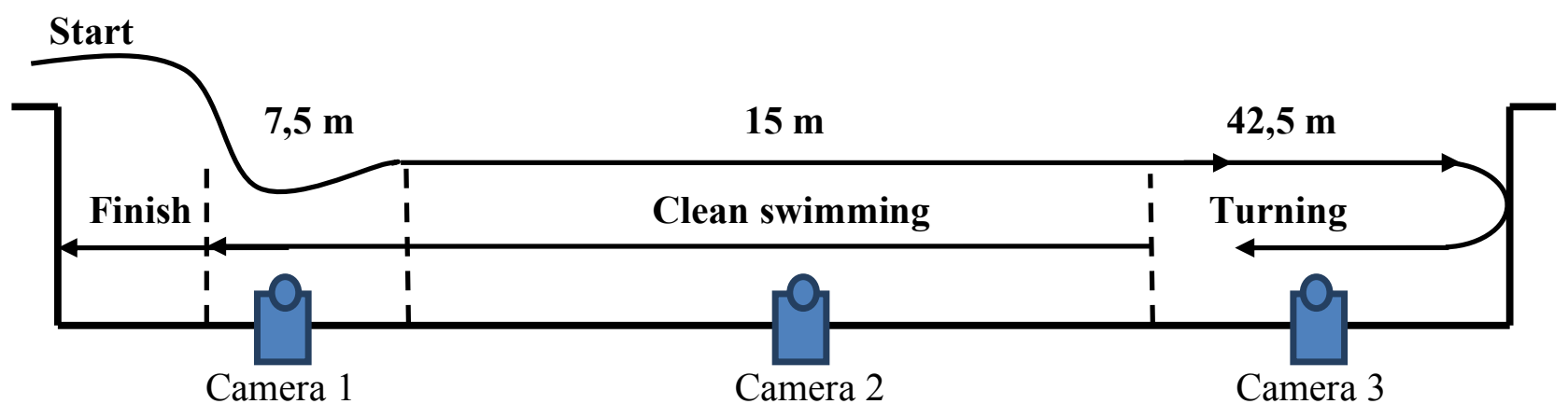

Figure 1. Scheme for cameras' setting up by section of the pool used in this study (adapted from Arellano and Sánchez, 2002).

Dartfish ${ }^{\circledR}$ software was used for swimmers' distance calculation, data treatment and image analysis. The variables studied were: CST1 and CST2, as a result of measuring the passage of the swimmers' heads over the imaginary line joining the references placed on the banks of the pool for each time segment; swimming speed in the first (CSS1) and second race segment (CSS2) were obtained following equations presented by Arellano et al., (1994) used to calculate the average swimming velocity per pool section (see Figure 1), as follows: V = $\mathrm{Li} / \mathrm{Ti}(\mathrm{m} / \mathrm{s}$; where $\mathrm{Li}=$ length in meters of the pool section of Lap $\mathrm{i}$, and $\mathrm{Ti}=$ time in seconds). To calculate CSS1, the distance used was $27.5 \mathrm{~m}$ and to calculate CSS2, the distance was $35 \mathrm{~m}$. SR was calculated from the time taken by the swimmer to perform three stroke cycles (T3cycles), based also on the procedure used by Arellano et al. (1994): SR = (3cycles / T3cycles) x 60. To determine SL (m/cycle), velocity was multiplied by SR. Then, SI was calculated as the result of the product of speed and SL.

For observation reliability measurement, swimming sequences were randomly selected from six different swimmers, registering variables directly and obtaining five times. Six points in each sequence were estimated, so that the total registrations for reliability assessment were 180 points. This process was repeated the next day on the same images. To check the degree of association between data from both observations, the Pearson correlation was applied on the total data analyzed in the two moments, providing a value of $r=0.98(\mathrm{p}<0.01)$, confirming observer reliability in this study.

\section{Statistical Analysis}

Kolmogorov-Smirnov and Levene tests were applied, and variables showed normal data distribution and homoscedasticity $(\mathrm{p}>0.05)$ respectively, so parametric statistics were applied. A descriptive analysis of the variables by calculating average (X) and standard deviation (SD) for each functional class and gender were carried out. To evaluate the differences between functional classes, an ANOVA plus a post hoc Scheffé test was used. 
Pérez-Tejero, J.; Almena, A.; Coterón, J.; Navandar, A., \& Veiga, S. (2018). Freestyle stroke parameters of national level swimmers with physical impairments. RICYDE. Revista internacional de ciencias del deporte. 53(14), 268-279. https://doi.org/10.5232/ricyde2018.05307

Spearman correlation coefficients were calculated to evaluate the degree of relationship between functional classification and SL, SR, SI and CSS. T-tests for dependent samples were calculated to evaluate differences between laps within each class. For calculations and statistical data processing, program SPSS 20.0 (SPSS Inc., Chicago, IL, USA) and the Microsoft Excel spreadsheet were used. The level of significance was set at alpha $\leq 0.05$.

\section{Results}

Stroking parameters (SR, SL and SI) and speed (CSS) measured during $100 \mathrm{~m}$ freestyle event are shown in Table 1 for male and female swimmers with physical impairment, grouped by functional class. In general, SR, SL, SI and CSS increased according to the functional class from S4 up to S10 in males and females. The mean difference by gender in a given class for CSS was $20.2 \%$ for classes S4, S7 and S8 (ranging from $38.8 \%$ in S4 up to 3,7\% in S8) and for SI was $34.4 \%$ for these classes (ranging from $54.2 \%$ in S4 up to $16,5 \%$ in S8), both positive for male with better performances. For class S10, stroking and time parameters by gender were almost identical, with slightly better results for females (see Table 1). SR values were not significantly different between male functional classes, but ANOVA found differences for SL, SI, CSS and TT within male classes (for SL and SI, S4 was significantly different from S10; for CSS, S4 was significantly different from S5, S8 and S10) and female classes (for SL, S4 was significantly different from S8 and S9; for SI, S4 was significantly different from S8, S9, and S10 and S7 was different from S9 and S10; for CSS, S4 and S7 were different from S8, S9 and S10; for TT, class S4 was different from other classes, and class S7 was different for S4 and S9). Finally, regarding SR, class S4 was found significantly different from S8 and S9 in female swimmers.

Table 1. Means and SD for stroke rate, stroke length, stroke index, clear swimming speed (CSS), total time and time difference between first and second race segment (Dif $50 \mathrm{~m}$ ), with indication of the correlations coefficients $(C C)$ among indicated parameters and the sport classes.

\begin{tabular}{|c|c|c|c|c|c|c|c|c|c|c|c|c|c|c|c|c|c|c|}
\hline \multirow{2}{*}{$\begin{array}{l}\text { Class } \\
\text { S4 }\end{array}$} & \multicolumn{3}{|c|}{$\begin{array}{l}\text { Stroke rate } \\
\text { (cycle/min) }\end{array}$} & \multicolumn{3}{|c|}{$\begin{array}{l}\text { Stroke length } \\
\text { (m/cycle) }\end{array}$} & \multicolumn{3}{|c|}{$\begin{array}{c}\text { Stroke index } \\
(\mathrm{m} / \mathrm{s}) \times(\mathrm{m} / \text { cycle })\end{array}$} & \multicolumn{3}{|c|}{$\begin{array}{l}\text { CSS } \\
(\mathrm{m} / \mathrm{s})\end{array}$} & \multicolumn{3}{|c|}{$\begin{array}{c}\text { Total time } \\
\text { (s) }\end{array}$} & \multicolumn{3}{|c|}{$\begin{array}{c}\text { Dif x lap } \\
\text { (s) }\end{array}$} \\
\hline & 53.23 & \pm & 13.48 & 1.05 & \pm & 0.47 & 1.00 & \pm & 0.75 & 0.87 & \pm & 0.25 & 120.69 & \pm & 24.04 & 7.90 & \pm & 2.09 \\
\hline S5 & 45.86 & \pm & 9.19 & 1.74 & \pm & 0.38 & 2.25 & \pm & 0.53 & 1.28 & \pm & 0.02 & 83.00 & \pm & 5.46 & 5.46 & \pm & 0.77 \\
\hline S6 & 46.48 & \pm & 4.03 & 1.48 & \pm & 0.17 & 1.72 & \pm & 0.39 & 1.14 & \pm & 0.15 & 94.37 & \pm & 7.52 & 6.46 & \pm & 3.06 \\
\hline S7 & 49.28 & \pm & 7.44 & 1.50 & \pm & 0.11 & 1.83 & \pm & 0.06 & 1.22 & \pm & 0.10 & 79.87 & \pm & 4.99 & 5.27 & \pm & 2.44 \\
\hline $\mathrm{S} 8$ & 52.23 & \pm & 14.66 & 1.58 & \pm & 0.35 & 2.07 & \pm & 0.45 & 1.31 & \pm & 0.06 & 75.03 & \pm & 3.62 & 3.69 & \pm & 2.20 \\
\hline $\mathrm{S} 10$ & 44.05 & \pm & 4.98 & 1.87 & \pm & 0.26 & 2.53 & \pm & 0.41 & 1.36 & \pm & 0.03 & 71.22 & \pm & 1.30 & 3.13 & \pm & 1.24 \\
\hline$C C$ & & & 0.36 & & & $0.90^{* *}$ & & & $0.94^{* *}$ & & & $0.87^{* *}$ & & & $-0.87^{* *}$ & & & -0.28 \\
\hline \multicolumn{19}{|c|}{ Males } \\
\hline $\mathrm{S} 4$ & 38.42 & \pm & 3.98 & 0.84 & \pm & 0.16 & 0.46 & \pm & 0.12 & 0.53 & \pm & 0.05 & 185.78 & \pm & 14.97 & 2.18 & \pm & 7.64 \\
\hline $\mathrm{S} 7$ & 49.46 & \pm & 5.36 & 1.23 & \pm & 0.18 & 1.24 & \pm & 0.25 & 1.00 & \pm & 0.06 & 97.71 & \pm & 5.46 & 6.42 & \pm & 0.92 \\
\hline S8 & 55.41 & \pm & 2.28 & 1.37 & \pm & 0.04 & 1.73 & \pm & 0.16 & 1.26 & \pm & 0.08 & 77.96 & \pm & 6.52 & 4.81 & \pm & 3.39 \\
\hline S9 & 52.55 & \pm & 5.42 & 1.60 & \pm & 0.21 & 2.23 & \pm & 0.40 & 1.39 & \pm & 0.08 & 70.32 & \pm & 4.55 & 2.89 & \pm & 1.56 \\
\hline $\mathrm{S} 10$ & 43.69 & \pm & 1.72 & 1.87 & \pm & 0.05 & 2.54 & \pm & 0.25 & 1.36 & \pm & 0.10 & 71.08 & \pm & 3.75 & 5.03 & \pm & 0.88 \\
\hline$C C$ & & & -.05 & & & $0.42^{*}$ & & & $0.49^{* *}$ & & & $0.58^{* *}$ & & & $-0.78^{* *}$ & & & $-0.57^{* *}$ \\
\hline \multicolumn{19}{|c|}{ Females } \\
\hline
\end{tabular}


Pérez-Tejero, J.; Almena, A.; Coterón, J.; Navandar, A., \& Veiga, S. (2018). Freestyle stroke parameters of national level swimmers with physical impairments. RICYDE. Revista internacional de ciencias del deporte. 53(14), 268-279. https://doi.org/10.5232/ricyde2018.05307

SL, SI, CSS values increased and TT decreased significantly $(\mathrm{p}<0.01)$ according to the functional class for both males and females from S4 up to S10; with the exception of the S5 male class, with better results (ns) than S8 in SI or than S7 for CSS. This is confirmed by the significant correlation coefficients obtained $50 \mathrm{~m}$ race segments were covered differently by swimmers, finding significant differences between both laps for males in SR $(\mathrm{p}<0.01)$, SL $(\mathrm{p}=0.023)$, and time per lap $(\mathrm{p}<0.01)$, while for females (see Table 1 and Figure 2$)$. Mean SI values were significantly $(\mathrm{p}<0.01)$ related to mean CSS values for male and female swimmers $(r=0.77$ and $r=0.94$, respectively), being the stroke parameter better related with the speed. Even more, total time was also significantly and inversely related to CSS $(r=-0.90$ for males and $r=-0.96$ for females). The two differences were found for SR ( $p<0.01)$, SI ( $p$ $=0.015)$, CSS $(p<0.01)$, and time per lap $(\mathrm{p}<0.01)$. The second $50 \mathrm{~m}$ half of the race slower than the first, with an average difference of $5.51 \pm 2.71 \mathrm{~s}$ for males and $4.04 \pm 3.65$ for females. These differences motivated us to analyse in deep the stroking variables and CSS by race segments, taking into consideration also sport class and gender in both $50 \mathrm{~m}$ race segments (Table 2).
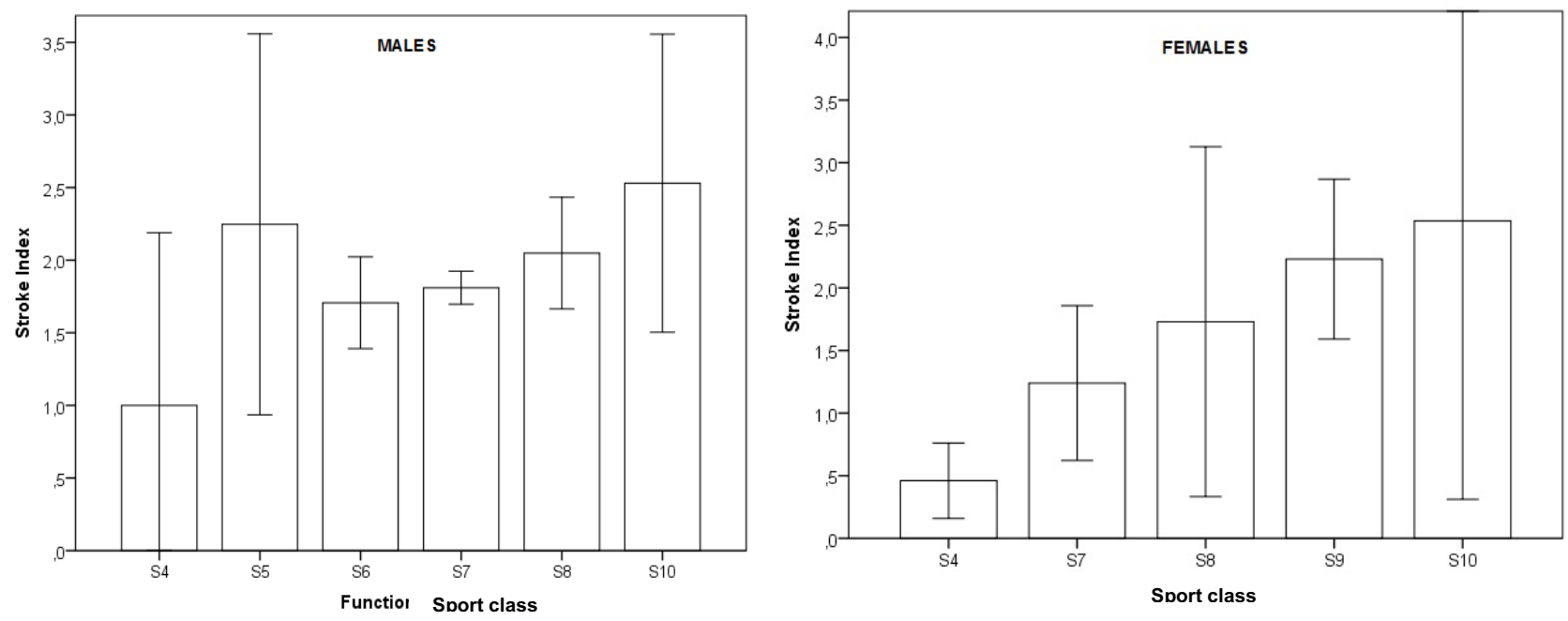

Figure 2. Evolution and comparison of stroke index by sport class for males and females (95\% CI). 
Pérez-Tejero, J.; Almena, A.; Coterón, J.; Navandar, A., \& Veiga, S. (2018). Freestyle stroke parameters of national level swimmers with physical impairments. RICYDE. Revista internacional de ciencias del deporte. 53(14), 268-279. https://doi.org/10.5232/ricyde2018.05307

Table 2. Means and SD for stroke rate, stroke length and stroke index for first (0-50 m) and second (50-100 m) segment of the $100 \mathrm{~m}$ freestyle swimming event, regarding swimmers' gender and sport class.

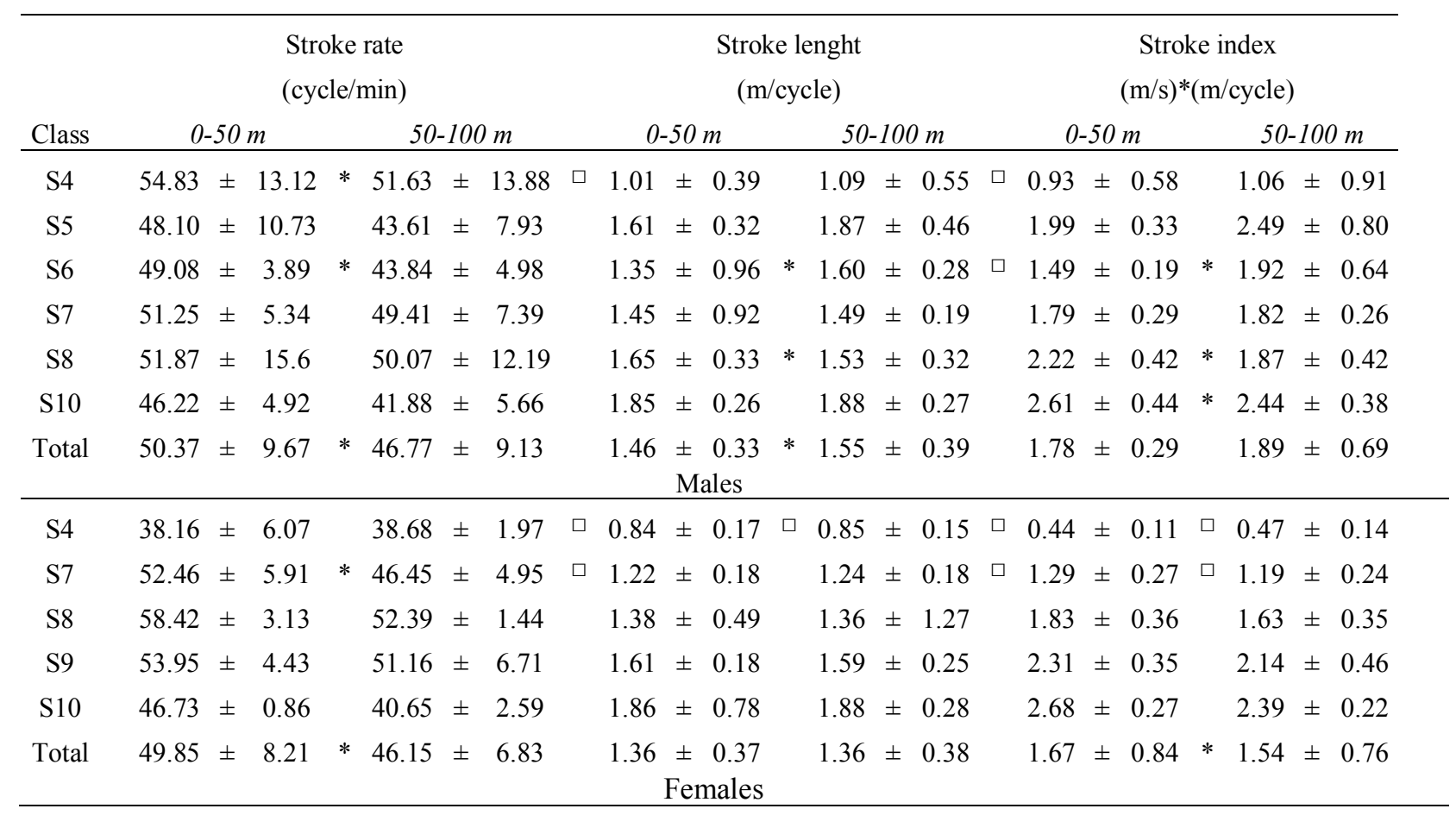

* Significant differences between first and second segment for the given parameter per sport class. $p<0.05$.

$\square$ Significant differences between sport classes within a given race segment by gender (see text for details). $p<0.05$.

Table 3. Means and SD for clear swimming speed and time for first (0-50 m) and second (50-100 m) segment of the $100 \mathrm{~m}$ freestyle swimming event, regarding swimmers' gender and sport class.

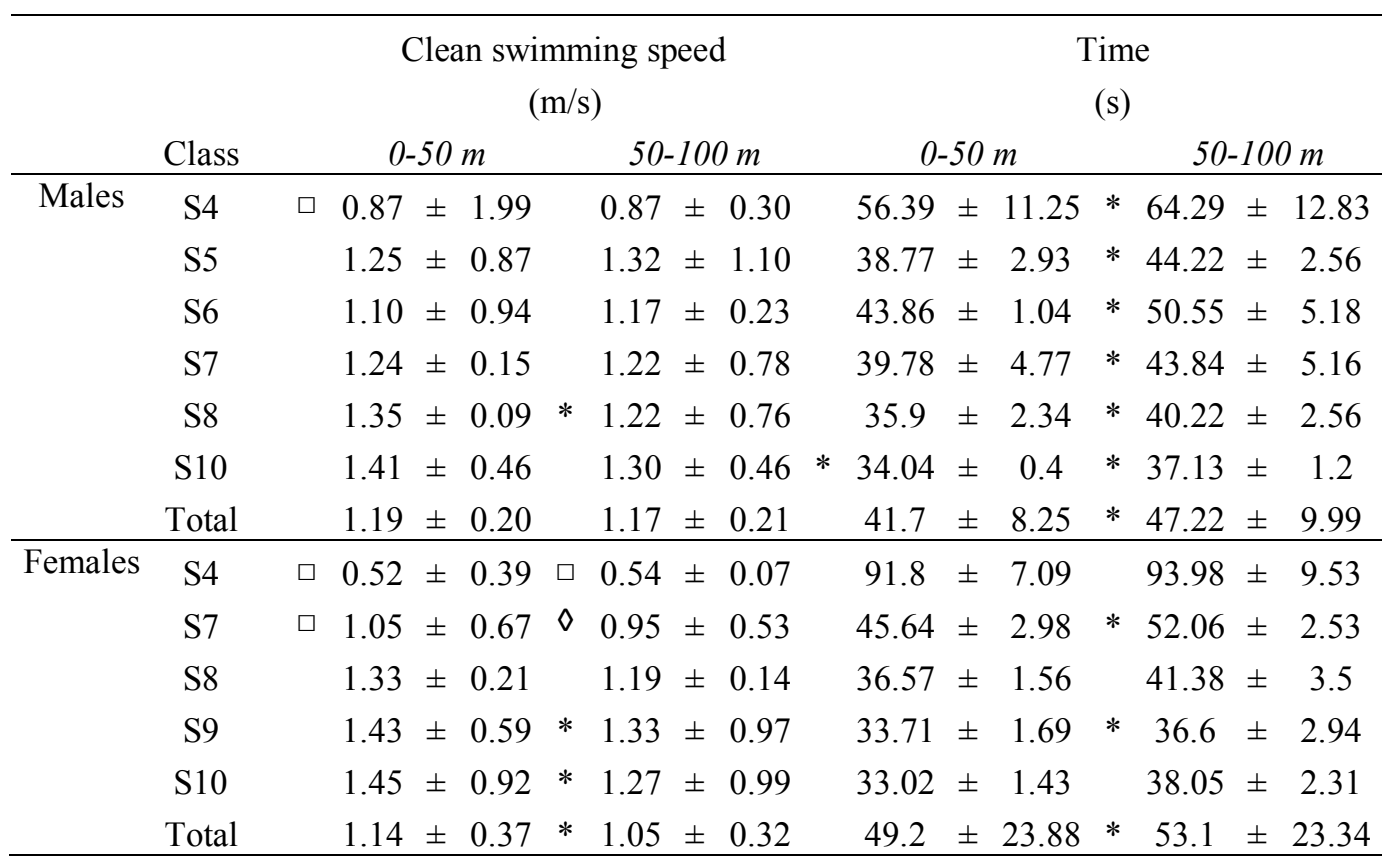

* Significant differences between first and second segment for the given parameter per functional class. $p<0.05$.

$\square$ Significant differences between functional classes within a given race segment by gender (see text for details). $p<0.05$

$\diamond$ Both previous significant differences. $p<0.05$. 
Pérez-Tejero, J.; Almena, A.; Coterón, J.; Navandar, A., \& Veiga, S. (2018). Freestyle stroke parameters of national level swimmers with physical impairments. RICYDE. Revista internacional de ciencias del deporte. 53(14), 268-279. https://doi.org/10.5232/ricyde2018.05307

Also, significant differences within each race segment were detected per sport class (see Table 2 and Table 3). For males, S4 class significantly differed from S8 and S10 classes in SL1, with classes S5, S7, S8 and S10 in CSS1, and with classes S5, S8 and S10 in SI1. At the same time, S6 class significantly differed with S8 and S10 classes in SI1. For females, S4 class significantly differed in SR1, SL1 and SL2 with S8 and S9 classes; in CSS1, CSS2 and SI1 with S7, S8, S9 and S10 classes; and in SI2 with S8, S9 and S10 classes. At the same time, S7 significantly differed S8, S9 and S10 classes in CSS1; with S9 and S10 classes in SI1 and CSS2; and with S10 class in SL1 and SI2.

\section{Discussion}

The $100 \mathrm{~m}$ freestyle event in swimmers with physical impairments has been studied on several occasions from the analysis of the kinematic variables and their interaction (Daly et al., 1999; Daly et al., 2003; Pelayo et al., 1999; Pérez-Tejero, Veiga, Almena, Navandar and Navarro, 2017) or its time features regarding variation and progression along different competitions (Fulton, Pyne, Hopkins, and Burkett, 2009). This is the only event in which all sport classes compete at Paralympic level, and it is the most popular (Daly et al., 1999). However, no studies has been found in the literature regarding the stroking profiling of these swimmers at national level, which compromises training references guidance and long term goal determination by gender and/or sport class. Moreover, Zwierzchowska and Gawli (2015) emphasized the need of practical studies in the field of sport for people with disabilities, so that contribute to the development of a support system for their training processes and, hence, to improve sports quality for this population. Thus, this investigation provides an original and pertinent focus, in order to frame swimming performance at this $100 \mathrm{~m}$ freestyle event, taking into consideration gender and sport class.

In our study, the main trend for all stroke parameters (unless SR) and CSS is a significant increment according to the sport class from lower to upper classes, being SI the parameter which best correlate with class in both genders. In this regard, SI has been defined as a fair indicator that measures the effectiveness and economy of swimming (Arellano and Sánchez, 2002) and it has been proposed as one of the main indicator of swimming efficiency in this population Pelayo et al. (1999); but despite knowing its importance, it has not been reevaluated since this last study in our population, who used it to characterize and to assess their progress in the different existing sport classes and gender in this $100 \mathrm{~m}$ event, comparing with an able-bodied sample of elite swimmers. They concluded that stroking parameters depend on sport class and gender, while SR was found similar between swimmers with and without impairments, but in those one, lower velocities were explained by lower SL values. In this regard, these authors suggest the use of SI as a practical criterion or reference to assess sport class, together with other methods used by classifiers in Paralympic swimming, noting it has a strong link with training status.

As in the previous study, in our sample of national level swimmers, CSS increases as the sport class increases, with strong differences by gender. In absolute values, when comparing SI data of this national level sample with elite sample in the study from Pelayo et al., (1999), there is a mean difference of 0,27 for males (classes S4, S7, S8 and S9) and a 0,16 for females (classes S4, S7, S8) in favour of elite swimmers. SI values were similar for S6 males classes $(1,7)$, but higher values were found in national level S9 and S10 female classes (main difference of 0,3$)$, especially between S5 male classes $(0,9)$, with higher SI values that those from elite swimmers. These authors suggested that significant differences in adjacent classes were not always present due to a possible overlapping effect, so this effect does not explain the values obtained by the class S5. Knowing there were 11 years of difference between 
Pérez-Tejero, J.; Almena, A.; Coterón, J.; Navandar, A., \& Veiga, S. (2018). Freestyle stroke parameters of national level swimmers with physical impairments. RICYDE. Revista internacional de ciencias del deporte. 53(14), 268-279. https://doi.org/10.5232/ricyde2018.05307

events analysed in both studies, for most part of functional classes there is still a considerable difference in SI performance in absolute values.

SR for males was similar in the different classes and did not differ significantly across them. In the case of females, significant differences between classes S4 and S8 and S9 were found in the SR1. As in the males, there were no significant differences between the studied classes. In this line, but in elite swimmers with impairments, previous studies conducted by Pelayo et al. (1999), Daly et al. (1999) and Daly, Malone, Vanlandewijck and Steadward (2001) showed how SR did not differ significantly between sport classes in both genders and how the SL and CSS increased significantly as did sport class in both genders, also in a similar way to this study.

One original analysis of this study is the stroke parameters, CSS and time comparison between the laps. Significant differences were found (see Table 2) in males between lap for SR (lower in second lap), SL (longer in second lap) and time (longer in second lap), while for females differences were found in SR (lower in second lap), SI and CSS (both lower in second lap) and time (longer in second lap). This fact appears as a different behaviour for females, not being able to maintain stroke length in the second lap (while males they are), but increasing significantly CSS. Pelayo et al. (1999) and Daly et al. (1999) found SL relevant in this event for elite swimmers with physical impairments, so these parameters should be used as performance indicator in long term development, especially in female swimmers. Within the same class, were significant differences between variables were not always found and differences varied according to the sport class and gender. According to Daly et al. (2003) there is no general technical pattern used, each swimmer finds one's own optimal solution to enhance one's best performance. That is why each swimmer would have to consider the type of impairment and how it affects these parameters. Huot-Marchand, Nesi, Sidney, Alberty, and Pelayo (2005) noted that in order to improve performance, top level swimmers could act on the interactions between the SR and SL. As a result of this, they determined that one could increase the SR and SL; increase one and stabilize the other parameter, or increase a parameter and decrease the other slightly. We do not know if this ability is present at the national level sample of this study. For time analysis, the second lap, by mean, was $5 \mathrm{~s}$ slower in men and $4 \mathrm{~s}$ slower than the first for all classes; in this regard, it seems that national level swimmers still have a potential to perform better times in the second lap by optimizing physical fitness, in order to maintain technical level of stroke parameters in the second part of the race.

Some studies have already shown the direct relationship between the SL and the CSS (Daly et al., 1999; Pelayo et al., 1999), and this fact has been confirmed also at national level, were SR was not significantly correlated with CSS, but SL and SI did $(p<0.01)$ for both genders. Dziuba, Kolodziej, and Zurowska (2013) proposed the use of the SI as a practical element and a quantitative measurement to evaluate the swimmer in the sport classification, ensuring a common starting point for swimmers in different classes. Therefore, the use of these variables, not only allows us to understand its evolution along the studied functional classes, but also provides useful information to the coaches and swimmers about their performance at national level and their potential to compete. Data from the stroke analysis could become a useful tool in order to optimize training plans, helping to find the optimal relationship between them to get the highest result considering swimmer sport class and impairment. 
Pérez-Tejero, J.; Almena, A.; Coterón, J.; Navandar, A., \& Veiga, S. (2018). Freestyle stroke parameters of national level swimmers with physical impairments. RICYDE. Revista internacional de ciencias del deporte. 53(14), 268-279. https://doi.org/10.5232/ricyde2018.05307

\section{Conclusions}

At national level $100 \mathrm{~m}$ freestyle event for swimmers with physical impairments, SI and SL appeared as the stroke parameters more directly related with sport class and CSS for both genders, while SR was not. Each swimmer, on the basis of his / her impairment, must find the optimum ratio between the two, so that their interaction is to obtain the highest speed possible. Within the same class, various combinations of the stroke parameters were observed in order to maintain CSS. Second lap was significantly slower than first for both genders in all sport classes. In addition, SI is suggested at this performance level as a key element to assess the effectiveness of each swimmer technique. Stroke and time parameters profiling of different sport classes and gender were provided, which are relevant for performance assessment, providing new insights for aims determination and swimmers long term development.

\section{References}

Arellano, R., \& Sánchez, J. A. (2002). El análisis de la competición: estudio de la situación actual, variables y metodología. In R. Arellano \& A. Ferro (Eds.). Análisis biomecánico de la técnica en natación: programa de control del deportista de alta competición. Madrid, Spain: Consejo Superior de Deportes, 9-15.

Arellano, R; Brown, P; Cappaert, J., \& Nelson, R. (1994). Analysis of 50-, 100-, and 200$\mathrm{m}$ freestyle swimmers at the 1992 Olympic Games. Journal of Applied Biomechanics, 10, 189-199. https://doi.org/10.1123/jab.10.2.189

Burkett, B. (2011). Contribution of sport science to performance-swimming. In Y.C. Vanlandewijck, Thompson, W.R. (Eds.), The Paralympic Athlete: Handbook of Sports Medicine and Science. West Sussex, UK: Wiley-Blackwell, 264-281. https://doi.org/10.1002/9781444328356.ch15

Craig, A. B., \& Pendergast, D. R. (1979). Relationships of stroke rate, distance per stroke, and velocity in competitive swimming. Medicine \& Science in Sports \& Exercise, 11(3), 278-283. https://doi.org/10.1249/00005768-197901130-00011

Craig, A. B.; Skehan, P. L., Pawelczyk, J. A., \& Boomer, W. L. (1985). Velocity, stroke rate, and distance per stroke during elite swimming competition. Medicine \& Science in Sports \& Exercise, 17(6), 625-634.

https://doi.org/10.1249/00005768-198512000-00001

Chengalur, S. N., \& Brown, P. L. (1992). An analysis of male and female Olympic swimmers in the 200-meter events. Canadian Journal of Sport Sciences, 17(2), 104109.

Chollet, D.; Pelayo, P.; Delaplace, C.; Tourny, C., \& Sidney, M. (1997). Stroking characteristic variations in the 100-M freestyle for male swimmers of differing skill. Perceptual and Motor Skills, 885(1), 167-177. https://doi.org/10.2466/pms.1997.85.1.167

Daly, D. Djobova, S.; Malone, L.; Vanlandewijck, Y., \& Steadward, R. (2003). Swimming speed patterns and strokes variables in the paralympic $100-\mathrm{m}$ freestyle. Adapted Physical Activity Quarterly, 20(3), 260-278. https://doi.org/10.1123/apaq.20.3.260

Daly, D., \& Martens, J. (2011). Competitive swimming and disabilities. In L. Seifert, D. Chollet and I. Mujika (Eds.), World Book of Swimming: From Science to Performance. New York: Nova Science Publishers, 459-480. 
Pérez-Tejero, J.; Almena, A.; Coterón, J.; Navandar, A., \& Veiga, S. (2018). Freestyle stroke parameters of national level swimmers with physical impairments. RICYDE. Revista internacional de ciencias del deporte. 53(14), 268-279. https://doi.org/10.5232/ricyde2018.05307

Daly, D.; Malone, L.; Smith, D.; Vanlandewijck, Y., \& Steadward, R (2001). The contribution of starting, turning, and finishing to total race performance in male paralympic swimmers. Adapted Physical Activity Quarterly, 18(3), 316-333.

https://doi.org/10.1123/apaq.18.3.316

Daly, D.; Malone, L.; Vanlandewijck, Y., \& Steadward R. (1999). Comparison of men's and women's $100 \mathrm{~m}$ freestyle performances at the 1996 Paralympic Games. In K.L.Keskinen, P. V. Komi, A. P. Hollander (Eds.), Biomechanics and Medicine in Swimming VIII. Jyväskyla, Finland: Gummerus Printing, 309-314.

Daly, D.; Malone, L.A.; Vanlandewijck, Y.; \& Steadward RD. Race analysis of paralympic swimmers: information for coaches and implications for classification. (2001). In G. Doll-Tepper, M. Kroner, \& W. Sonnenschein (Eds.), New Horizons in Sport for Athletes with a Disability: VISTA 99. Aachen, Germany: Meyer \& Meyer Sport, 97-110.

Djobova, S.; Mavromati, A., \& Daly, D. (2002). Performance evolution in Paralympic freestyle swimmers. European Bulletin of Adapted Physical Activity, 1(1), 1-10.

Dziuba, A.; Kolodziej, A., \& Zurowska, A. (2013). Kinematic analysis as a part of objective method of functional classification in disability swimming - Pilot studies. Baltic Journal of Health and Physical Activity, 5(3), 176-183.

https://doi.org/10.2478/bjha-2013-0016

Elferink-Gemser, M. T.; Kannekens, R.; Lyons, J.; Tromp, Y., \& Visscher C. (2010). Knowing what to do and doing it: Differences in self-assessed tactical skills of regional, sub-elite, and elite youth field hockey players. Journal of Sport Sciences, 28(5), 521-528.

https://doi.org/10.1080/02640410903582743

Fulton, S. K.; Pyne, D.; Hopkins, W., \& Burkett, B. (2009). Variability and progression in competitive performance of Paralympic swimmers. Journal of Sport Sciences, 27(5), 535-539.

https://doi.org/10.1080/02640410802641418

Hay, J. G., \& Guimares, A. C. S. (1983). A quantitative look at swimming biomechanics. Swimming Technique, 1, 11-17.

Huot-Marchand, F.; Nesi, X.; Sidney, M.; Alberty, M., \& Pelayo, P. (2005). Variations of stroking parameters associated with $200 \mathrm{~m}$ competitive performance improvement in top-standard front crawl swimmers. Sports Biomechanics, 4(1), 89-100. https://doi.org/10.1080/14763140508522854

International Paralympic Committee (2015). Swimming classification rules and regulations. Retrieved June 4, 2017 from:

http://www.paralimpicos.es/publicacion/ficheros/NAT\%202015\%20September\%20IPC\% 20Swimming\%20Classification\%20Rules\%20Regulations.pdf

International Paralympic Committee (2015b). Swimming, rules and regulations 20142017. Retrieved June 4, 2017 from:

https://www.paralympic.org/sites/default/files/document/151109162936023_2015_02+ IPC+Swimming+Rules+and+Regulations_V3.pdf

Malone, L. A.; Sanders, R. H.; Schiltz, J. H., \& Steadward, R. D. (2001). Effects of visual impairment on stroke parameters in Paralympic swimmers. Medicine \& Science in Sports \& Exercise, 33(12), 2098-2103. https://doi.org/10.1097/00005768-200112000-00019

Nasirzade, A.; Sadeghi, H; Sobhkhiz, A.; Mohammadian, K.; Nikouei, A.; Baghaiyan, M., \& Fattahi, A. (2015). Multivariate analysis of 200-m front crawl swimming performance in young male swimmers. Acta of Bioengineering and Biomechanics, 17(3), 137-143. 
Pérez-Tejero, J.; Almena, A.; Coterón, J.; Navandar, A., \& Veiga, S. (2018). Freestyle stroke parameters of national level swimmers with physical impairments. RICYDE. Revista internacional de ciencias del deporte. 53(14), 268-279. https://doi.org/10.5232/ricyde2018.05307

Pai, Y. C.; Hay, J. G., \& Wilson, B. D. (1984). Stroking techniques of elite swimmers. Journal of Sport Sciences, 2(3), 225-239.

https://doi.org/10.1080/02640418408729719

Pelayo, P.; Sidney, M.; Moretto, G.; Wille, F., \& Chollet, D. (1999). Stroking parameters in top level swimmers with a disability. Medicine \& Science in Sports \& Exercise, 31(12), 1839-1843.

https://doi.org/10.1097/00005768-199912000-00022

Pérez-Tejero, J.; Veiga, S.; Almena, A.; Navandar, A., \& Navarro, E. (2017). Effect of functional classification on the swimming race segments during the 2012 London Paralympic Games. International Journal of Performance Analysis in Sport, 17(4), 112.

https://doi.org/10.1080/24748668.2017.1348059

Tweedy, S. M., \& Vanlandewijck, Y. C. (2011). International Paralympic Committee position stand - background and scientific principles of classification in Paralympic sport. British Journal of Sports Medicine, 45(4), 259-269. https://doi.org/10.1136/bjsm.2009.065060

Veiga, S.; Cala, A.; Mallo, J., \& Navarro, E. (2013). A new procedure for race analysis in swimming based on individual distance measurements. Journal of Sport Sciences, 31(2), 159-165. https://doi.org/10.1080/02640414.2012.723130

Zwierzchowska, A., \& Gawlik, K. (2015). Sport and disabled individuals - theory and practice. Journal of Human Kinetics, 48(1), 5-6.

https://doi.org/10.1515/hukin-2015-0085 